saccharides. S. Cohen and R. R. Porter describe the chemistry and biological function of $19 S$ and $7 S \gamma$ globulin and of the three pieces obtainable from $7 S^{t}$ $\gamma$-globulin by enzymatic digestion: piece 3 with its capacity to sensitize skin and promote placental transfer, and pieces 1 and 2 with their antibody combining sites and allotypic specificity. These findings add to the interest of B. N. Halpern's work on "Le processus de Sensibilization', showing the remarkable competition for cellular attachment between normal $\gamma$-globulin and antibody $\gamma$-globulin. D. H. Campbell discusses the importance of antigen-antibody ratios for the tissue reactions produced by their complexes. J. Humphrey discusses biochemical mediators of antigen-antibody reactions, with reference to two performed mediators. histamine and serotonin, two produced mediators, $S R S-\mathrm{A}$ and bradykinin, and complement-fixing esterase activation in anaphylaxis.

Immunological and clinical aspects of drug hypersensitivity are discussed with an introduction by $\mathbf{M}$. W. Chase on chemical considerations. In reviewing the immune response of hypersensitivity, S. Raffel concludes that the early appearing Jones-Mote type of sensitivity to protein antigens is probably of the delayed tuberculin type. L. E. Thomas argues that the teleological significance of delayed-type hypersensitivity is protective, by destroying potentially neoplastic cells. S. B. Salvin and H. N. Eisen discuss delayed-type sensitivity to protein and simple chemicals respectively.

In the section on auto-allergy, homograft rejection is discussed by E. Billingham, hypogammaglobulinæmia and immunological responses by C. A. Janeway, and autosensitization to thyroid and to vascular antigens by E. Witebsky and D. Pressman respectively, with a paper on the inhibition of immune reactions by $J$. Sterzl.

Useful reviews of techniques are given, on the measurement of antibody by D. W. Talmage, and on hrmagglutinating factors in allergie sera by A. H. Sehon. Agar-gel, immunoelectrophoretic and fluorescent antibody techniques are well covered by J. Oudin, P. Burtin and M. H. Kaplan respectively. The uses and interpretations of the passive cutaneous test for anaphylaxis are discussed by Z. Ovary, and O. G. Bier concludes with a critical discussion of the rôle of complement-fixation in immediate hypersensitivity reactions.

The discussions on the clinical use of steroids, psychotherapy, general methods and the use of mineral oil emulsions for 'desensitization' show the need for more precise investigations in these fields.

J. PePYS

\section{DISCUSSIONS OF STATISTICAL INFERENCE}

The Foundations of Statistical Inference

A Discussion. Opened by Prof. L. J. Savage. (Methuen's Monographs on Applied Probability and Statisties.) Pp. 112. (London: Methuen and Co., Ltd., New York: John Wiley and Sons, Inc., 1962.) 15s. net.

$\mathrm{T}$ HIS monograph is divided into three parts. In the first, Prof. L. J. Savage expounds his views on statistical inference, arguing that all statistical practice should be based on Bayes's theorem, that there is no dichotomy of statistical problems into mference or decision, and that all probabilities are "subjective". In the second, five eminent British statisticians (Profs. Bartlett, Barnard, Cox, Pearson and. Dr. C. A. B. Smith) present their views on this topic and then, in the third part, the discussion at the seminar at which these lectures were given is recorded.

The dust jacket proclaims "most of the monograph is non-technical and should interest anyone concerned with statistical inference". Both these statements are true.
There are very informative discussions of such purely "objectivist" problems as testing a simple hypothesis without specifying an alternative. On this topic, for example, Prof. Cox points out that in a great many "testing situations" any test-statistic will itself generate a family of alternative hypotheses against which it is "optimum"; one is left wondering whother it would not always be better to make some attempt to specify alternatives rather than have it done, so to speak, for one. The major part of the monograph is, however, taken up with the discussion of points of disagreement between the subjectivists and the objectivists, and here the nontechnical nature of the monograph hes, I think, been taken too far.

There is no statement of the basic axioms used and of the major results derived by Prof. Savage in his book The Foundations of Statistics. This makes the outline of the area of disagreement unnecessarily vague, which means that certain parts of the discussion will not appear fruitful to a reader unacquainted with a formal statement of Savage's position. Indeed an explicit statement of the axioms and the main result in The Foundation of Statistics would, I think, have helped in the diseussion itself. For example, a direct attack on the axioms or the derivation of the main result would then have been called for, which might have cleared the way to a better understanding of where the points of disagreement lie.

The discussion is, however, always interesting and the book is well worth buying on a number of counts. For example, for the discussion on the difference between the precision expected from an experiment before it is performed and the precision actually yielded by it when it is performed, and for Prof. Barnard's discussion on likelihood functions and their interpretation. The reader will find the monograph more rewarding, however, if the first few chapters of Prof. Savage's book and the paper of Prof. A. Birnbaum are read first. The book deals with a "decision" or "potential decision" situation and the subjective probability distributions derived are really shorthand descriptions of "betting" behaviour. An understanding of this should help one to decide, for example, whether in fact Prof. Savage's discussion on inference derives backing from his book, and whether Prof. Barnard is in fact at cross-purposes with Prof. Savage when he states (p. 41) "Whoever manages to guess the prior distribution most accurately will obtain the best decision rule". Finally, Prof. Birnbaum's paper based on purely "objectivist" jdeas, proves, on the basis of some apparently compelling axioms, that "objectivist inference" should be based on the likelihood function alone, and it is interesting to follow the discussion with this latter result in mind.

M. C. PIKe

'Birnbaum, A., On the Foundations of Statistical Inference. J. Amer. Stat. Assoc., 57, 269 (1962).

\section{SYMPOSIUM ON SPACE SCIENCE}

\section{Space Research III}

Proceedings of the Third International Space Science Symposium, Washington, D.C., May 2-8, 1962. (Organized by the Committee on Space Research-Cospar, and the U.S. National Academy of Sciences.) Edited by Prof. Wolfgang Priester. Pp. xvi + 1275. (Amsterdam: NorthHolland Publishing Company, 1963.) $220 s$.

HIS volume contains most of the papers presented at the third International Space Science Symposium at Washington in May 1962. It does not include the papers on life sciences or the contributions to the two related international conferences at Washington which immediately preceded the Symposium, namely, those on "Rocket and Satellite Meteorology" and on the "Use of Artificial Satellites for Geodesy". The papers on these topics are being published in three separate volumes. 